\title{
A Note on Economic Burden of Diabetes of Adults at Household Level
}

\author{
KC Bhuyan* \\ Professor of Statistics, Jahangirnagar University, Dhaka, Bangladesh \\ *Corresponding Author: KC Bhuyan, Professor of Statistics, Jahangirnagar University, Dhaka, Bangladesh.
}

Received: October 23, 2019; Published: November 12, 2019

DOI: $10.31080 /$ ASNH.2019.03.0541

\begin{abstract}
The results of the present note were based on data collected from 808 adults of Bangladesh by some doctors and nurses according to their convenience. Among the investigated adults, 49.6 percent were suffering from at least one of the non-communicable diseases and 55.9 percent of them were exclusively suffering from diabetes and among the exclusive diabetic patients 41.5 percent were overweight and obese against the overall 36.6 percent obese and overweight in the sample. The financial loss of diabetic patients was Tk.2916.67 per month for treatment and this amount was 3.7 percent of their average monthly income. They lost, on an average, 4.97 working days or 39.76 working hours due to admission into the hospital for treatment. This was an opportunity loss for the family. The economic loss and the opportunity loss together was the economic burden of the family.

Keywords: Overweight and Obesity; Diabetes; Economic Loss due to Treatment; Opportunity Loss due to Hospital Admission
\end{abstract}

\section{Introduction}

Diabetes is one of the major problem creating component of NCDs worldwide. This disease is associated with overweight and obesity, unhealthy food habit, sedentary activities, physical inactivity, etc. [1- 8]. NCDs kill 41 million people which is equivalent to 71 percent annual of all deaths [9]. Out of these 41 million people, 1.6 million death is due to diabetes. In a separate study, it was observed that most of the Bangladeshi urban adults (36.3\%) were suffering from diabetes [9]. The prevalence of diabetes in adults (20 - 79 years of age) was 7.4 percent in Bangladesh [11,12]. According to International Diabetes Federation the prevalence will be 13 percent by $2030[13,14]$.

The increasing trend of rate of diabetes is the alarming situation worldwide and specially it is alarming for low-and -middleincome countries [15-20]. It indicates that there will be rapidly growing burden of NCDs in developing countries. The problem is accelerated by population ageing, negative effects of globalization (unfair trade and irresponsible marketing), rapid and unplanned urbanization. Thus economists are increasingly expressing concern that NCDs will result in long term macroeconomic impacts on labor supply, capital accumulation and GDP worldwide with the consequences most severe in developing countries [15-20]. Globally, the labor units lost owing to NCDs deaths and the direct medical cost of treating NCDs have reduced the quality and quantity of labor force and human capital [21].

At the household level, unhealthy sedentary activities, unhygienic food habit and the high cost of NCDs related health care, lead to loss of household income $[15,16]$. Out-of pocket expenditure as- sociated with the acute long term effects of NCDs is high, resulting in catastrophic health expenditure for the households $[15,16]$.

The macroeconomic impact of NCDs is profound due to significant loss of productivity caused by NCDs related premature deaths and treatments [18]. The economic burden on households of NCDs including diabetes and CVD poses major challenges in alleviating poverty. In this note, attempt was made to guess the economic and opportunity loss due to prevalence of diabetes among a group of Bangladesh Adults.

\section{Methodology}

In this note analytical results were presented using the data collected from 808 adults of Bangladesh who were investigated by some doctors and nurses from their working places according to their convenience. The data were collected during academic session 2016-2017 when the investigators were continuing their academic carrier as M.P.H students. The investigators were instructed to collect information from the persons of ages 18 years and above. The data were recorded through a pre-designed and pre-tested printed questionnaire. The collected information from all the investigated adults were related to different socioeconomic variables including monthly family income, family expenditure and yearly family expenditure on treatment of non-communicable diseases. The data on hospital admission of investigating units for treatment of any of the NCDs were also recorded. Some of the variables were qualitative in nature. But for analytical purpose all the variables were noted in nominal scores.

In some studies, both in home and abroad, it was noted that NCDs were associated with body mass index (BMI) $[2,3,5,6,11,12]$. 
The body mass index was measured by weight in $\mathrm{kg} /$ height in $(\mathrm{m})^{2}[3,9,10]$. The adults were classified as underweight $[\mathrm{BMI}<20]$, normal weight $[\mathrm{BMI}=20-<25]$, overweight $[\mathrm{BMI}=25-<30]$ and obese [BMI > 30] [9]. The equality of proportions of diabetic patients of different levels of obesity was investigated by chi-square test, where heterogeneity in the proportions was decided when p- value of the Chi-square test statistic $\leq 0.05$. The average family income, average family expenditure and average cost of treatment per family of diabetic patients and average loss of working hours by the diabetic patients due to hospital admission were calculated to guess the financial and opportunity loss.

\section{Results}

Among the investigated adults 27.7 percent were diabetic patients (Table 1) and 50.4 percent were free of any NCDs. The remaining 21.9 percent were suffering from multiple diseases. In the sample, 36.6 percent adults were overweight and obese and this percentage among diabetic patients was 41.5.There was significant association between level of obesity and types of NCDs [ = 26.428 , p-value $=000]$. Significant differences in the proportions of diabetic patients according to different levels of obesity were also observed $[=108.68, \mathrm{p}$ - value $=0.000]$.

The average monthly income of the families of investigating adults was Tk.76,373.76 with standard deviation $=$ Tk.36,883.13.
The corresponding figures for diabetic patients were Tk.78,883.93 and Tk.35,135.01. The majority (58.3\%) of the families had monthly income Tk.90,000 or more. The percentage of diabetic patients having such amount of income was 59.8. However, the level of income and level of NCDs was not significantly associated [ = 11.513, $\mathrm{p}$-value $=0.073]$.

The monthly family expenditure of the adults was Tk.52,227.72 with standard deviation of Tk.11,477.49. This expenditure in the families of exclusively diabetic patients was Tk.52,276.79 with standard deviation of Tk.10,823.02. This monthly expenditure did not include the cost of medical treatment.

It was already been mentioned that 50.4 percent adults were free of disease. Though 49.6 percent were suffering from at least one of the non-communicable diseases, only 35.3 percent adults were admitted to the hospital for treatment. This amount of admitted patients was 71.1 percent of the NCDs affected adults. On an average, the patients were staying for 4.72 days ( $=4.35$ days ) in the hospital and they lost around 37.76 labor hours due to hospital admission. The diabetic patients were treated, on an average, for 4.97 days in the hospital resulting an opportunity loss of 39.76 labor hours.

For all patients, the average yearly expenditure for treatment was Tk. 36,362.50 (Table 2) with standard deviation of Tk.

\begin{tabular}{|c|c|c|c|c|c|c|c|c|}
\hline \multirow{3}{*}{ Level of obesity } & \multicolumn{6}{|c|}{ Type of non-communicable diseases } & \multicolumn{2}{|c|}{ Total } \\
\hline & \multicolumn{2}{|c|}{ None } & \multicolumn{2}{|c|}{ Diabetes } & \multicolumn{2}{|c|}{ Others } & \multirow{2}{*}{$\mathbf{N}$} & \multirow{2}{*}{$\%$} \\
\hline & $\mathbf{N}$ & $\%$ & $\mathbf{n}$ & $\%$ & n. & $\%$ & & \\
\hline Underweight & 73 & 68.2 & 23 & 21.5 & 11 & 10.3 & 107 & 13.2 \\
\hline Normal & 211 & 52.1 & 108 & 26.7 & 86 & 21.2 & 405 & 50.1 \\
\hline Overweight & 111 & 42.5 & 79 & 30.3 & 71 & 27.2 & 261 & 32.3 \\
\hline Obese & 12 & 34.3 & 14 & 40.0 & 9 & 25.7 & 35 & 4.3 \\
\hline Total & 407 & 50.4 & 224 & 27.7 & 177 & 21.9 & 808 & 100.0 \\
\hline \multicolumn{9}{|c|}{ Monthly family income (in 000 taka) } \\
\hline$<30$ & 96 & 60.4 & 36 & 22.6 & 27 & 17.0 & 159 & 19.7 \\
\hline $30-60$ & 55 & 47.4 & 33 & 28.4 & 28 & 24.1 & 116 & 14.3 \\
\hline $60-90$ & 23 & 37.1 & 21 & 33.9 & 18 & 29.0 & 62 & 7.7 \\
\hline $90^{+}$ & 233 & 49.5 & 134 & 28.5 & 104 & 22.1 & 471 & 58.3 \\
\hline \multicolumn{9}{|c|}{ Monthly family expenditure (in 000 taka) } \\
\hline$<40$ & 109 & 58.0 & 41 & 21.8 & 38 & 20.2 & 188 & 23.3 \\
\hline $40-50$ & 69 & 46.9 & 47 & 32.0 & 31 & 21.1 & 147 & 18.2 \\
\hline $50-60$ & 82 & 44.3 & 68 & 36.8 & 35 & 18.9 & 185 & 22.9 \\
\hline $60^{+}$ & 147 & 51.0 & 68 & 23.6 & 73 & 25.3 & 288 & 35.6 \\
\hline \multicolumn{9}{|c|}{ Number of days stayed in the hospital } \\
\hline None & 407 & 100.0 & 70 & 31.3 & 46 & 26.0 & 523 & 64.7 \\
\hline 1 & 0 & 0.0 & 16 & 7.1 & 16 & 9.0 & 32 & 4.7 \\
\hline 2 & 0 & 0.0 & 46 & 20.5 & 47 & 26.6 & 93 & 11.5 \\
\hline$<7$ & 0 & 0.0 & 47 & 21.0 & 37 & 20.9 & 84 & 18.4 \\
\hline 7 & 0 & 0.0 & 27 & 12.1 & 18 & 10.2 & 45 & 5.6 \\
\hline $8-<15$ & 0 & 0.0 & 10 & 4.5 & 8 & 4.5 & 18 & 2.2 \\
\hline $15^{+}$ & 0 & 0.0 & 8 & 3.6 & 5 & 2.8 & 13 & 1.6 \\
\hline
\end{tabular}

Table 1: Distribution of adults according to some socioeconomic characteristics and type of non-communicable diseases. 


\begin{tabular}{|c|c|c|c|c|c|c|c|c|}
\hline \multirow{3}{*}{ Yearly expenditure of treatment (in 000 taka) } & \multicolumn{6}{|c|}{ Type of non-communicable diseases } & \multicolumn{2}{|c|}{ Total } \\
\hline & \multicolumn{2}{|c|}{ None } & \multicolumn{2}{|c|}{ Diabetes } & \multicolumn{2}{|c|}{ Others } & \multirow{2}{*}{$\mathbf{N}$} & \multirow{2}{*}{$\%$} \\
\hline & $\mathbf{N}$ & $\%$ & $\mathbf{n}$ & $\%$ & n. & $\%$ & & \\
\hline Nil & 407 & 99.8 & 0 & 0.0 & 1 & 0.2 & 408 & 50.5 \\
\hline$<10$ & 0 & 0.0 & 36 & 69.2 & 16 & 30.8 & 52 & 6.4 \\
\hline $10-20$ & 0 & 0.0 & 44 & 51.8 & 41 & 48.2 & 85 & 10.5 \\
\hline $20-40$ & 0 & 0.0 & 56 & 56.6 & 43 & 43.4 & 99 & 12.3 \\
\hline $40-60$ & 0 & 0.0 & 42 & 58.3 & 30 & 41.7 & 72 & 8.9 \\
\hline $60^{+}$ & 0 & 0.0 & 46 & 50.0 & 46 & 50.0 & 92 & 11.4 \\
\hline Total & 407 & 50.4 & 224 & 27.7 & 177 & 21.9 & 808 & 100.0 \\
\hline
\end{tabular}

Table 2: Distribution of adults according to yearly expenditure of treatment and type of non-communicable diseases.

11.060.34. The monthly medical expenditure was Tk. 3030.31. This amount was approximately 4 percent of the family income. The expenditure for medical treatment of diabetic patients was Tk.35,000.00 per annum. The monthly medical expenditure of them was Tk.2916.67. This amount was 3.7 percent of their monthly family income. The percentage of diabetic patients spending Tk. 40,000.00 and above per year was 39.3.

\section{Discussion}

In developing countries the burden of NCDs is in increasing trend due to change in lifestyle misusing resources for unhygienic and unhealthy foods and drinks. People are becoming habituated in taking junk food and calorie dense food with more sugar and salt. Beside these, the sedentary activities and physical inactivity are the risk factors for overweight and obesity which in turn exposes people to NCDs. Thus in many studies in home and abroad social and economic factors[11,23, 24,25] were identified as the cause of NCDs as these were found associated with overweight and obesity. With the upward movement of income the rates of NCDs affected people were in increasing trend creating economic burden to the family [26]. The present analysis was an attempt to study the economic burden of families of adults suffering from diabetes. Out of 808 investigated adults 27.7 percent were diabetic patients and the families of diabetic patients faced a cash economic loss of 3.7 percent of their monthly income as treatment cost. This loss along with opportunity loss of 39.76 labor hours were the economic burden to the family.

\section{Conclusion}

The analysis presented here was based on data collected from 808 adults by some doctors and nurses from and around their working places. During analysis the adults were classified by the prevalence of non-communicable diseases and for this analysis the exclusive diabetic patients were identified. These patients were 27.7 percent of the sample units and 55.9 percent of the NCDs affected (49.6\%) adults. Another 21.9 percent adults were suffering from multiple diseases including diabetes. According to the objective of the study, the economic aspects, specially, the economic burden of exclusively diabetic patients was presented here. The monthly medical expenditure of the diabetic patients was Tk.
2926.67. This amount was 3.7 percent of their monthly income. In a large scale study this type of cost was $3.58 \%$ of GDP [20]. This is an economic loss to the family. Beside this loss, the diabetic adult lost, on an average, 4.97 working days or 39.76 labor hours due to hospital admission. This labor hours was approximately the national weekly labor hours (39 hours) [22]. This is an opportunity loss to the family. The economic loss due to treatment and the opportunity loss was the total economic burden to the household.

The economic burden of diabetes can not be avoided but it can be reduced to a great extent if some actions are taken for developing hygienic and sound health policy. Some of the hygienic aspects for human being are

- As diabetes is a component of NCDs and NCDs are associated with obesity, the people are to be advised to control their body weight through diet control and physical activity,

- People should avoid rich food which are full of sugar, salt and high calorie,

- People can take home made food containing more fresh vegetables as per as possible,

- People should avoid restaurant and can food,

- People should be suggested and motivated for joining health screening program, if there is any.

Civil society can play a vital role to alert the people against the danger of NCDs.

\section{Bibliography}

1. Zhang QL and Rothon bacher D. "Prevalence of kidney disease in population -based studies: Systematic review". BMC Public Health 8 (2008): 117.

2. Saquib N., et al. "Cardiovascular diseases and type II diabetes in Bangladesh: a systematic review and meta- analysis of studies between 1995-2010". BMC Public Health 12 (2012): 434.

3. Bhuyan KC., et al. "Socioeconomic factors associated with overweight an obesity: A case study among adult people of Bangladesh". AJSE 16 (2017): 119-124. 
4. Bhuyan KC., et al. "Discriminating the students of universities by their smoking habit". AJSE 15 (2016).

5. Chow K., et al. "Prevalence, awareness, treatment and control of hypertension in urban and rural communities in high - , middle-and low-income countries". JAMA (2013).

6. Bhuyan KC., et al. "Relationship between socioeconomic factors and diabetes among urban and rural people of Bangladesh". Global Journal of Quantitative Science (2016).

7. Silink M., et al. "Prevention and control of diabetes with a focus on low and middle income countries, paper 6, A prioritized research agenda for prevention and control of noncommunicable diseases". WHO (2011).

8. Prakashchandra RD and Naido DP. "Glycaemic control profile in diabetic patients: A sub-analysis of the phoenix lifestyle project". Euromediterranean Biomedical Journal 11 (2016): 33-39.

9. WHO. Fact sheets/detail/obesity-and-overweight (2018).

10. Paymane A and Miranda P. "Images of measurements of obesity". BMJ 360 (2018).

11. Akter S., et al. "Prevalence of diabetes and pre-diabetes and their risk factors among Bangladeshi adults: A Nationwide survey". Bulletin of the WHO 92 (2014): 204-213 A.

12. Biswas T., et al. "Overweight and obesity among children and adolescents in Bangladesh: a systematic review and meta analysis". Public health 142 (2017): 94-101.

13. International Diabetes Federation (IDF): Country estimates table, IDF Diabetes atlas, 6th edition (2011).

14. Karar ZA., et al. "Epidemiological transition in rural Bangladesh". Global Health Action 19 (2009): 2.

15. Abegunde DO and Stanciole A. An estimation of the economic impact of chronic non-communicable diseases in selected countries. WHO Working Paper, Geneva, World Health Organization, Department of Chronic Diseases and Health Promotion (2006).

16. Abegunde DO., et al. "The burden and costs of chronic diseases in low-income and middle-income countries". Lancet 370 (2007): 1929-1938.

17. Ramchandran A and Ramchandran S. "Increasing expenditure on health care incurred by diabetic subjects in a developing country : a study from India". Diabetes Care 30 (2007): 252256.

18. Barcelo A., et al. "The cost of diabetes in Latin America and the Caribbean". Bulletin of the World Health Organization 81 (2003): 19-27.
19. Zhang P., et al. "Global health care expenditure on diabetes for 2010 and 2030". Diabetes Research and Clinical Practice 87 (2010): 293-301.

20. Popkin BM and Soowon K. "Measuring the full economic costs of diet, physical activity, and obesity-related chronic diseases". Obesity Reviews 7 (2006): 271-293.

21. Mayer-Foulkes D. "A survey of Macro Damages from Non-Communicable Chronic Diseases: Another Challenges for Global Governance". Global Economy Journal 11 (2011).

22. Bangladesh Statistics -2. Bangladesh Bureau of Statistics, Government of People's Republic of Bangladesh, Dhaka (2017).

23. Mokdad AH., et al. "Prevalence of obesity, diabetes, and obesity-related health risk factors 2001”. JAMA 289 (2003): 76-79.

24. Bertino B., et al. "Obesity and related diseases: an epidemiological study in Eastern Sicily". Minerva Gastroenterologica e Dietologica 52 (2006): 379-385.

25. Calamusa G., et al. "Body mass index and factors associated with overweight and obesity: a cross-sectional study of adult subjects living in a small city of Western Sicily (Italy)". Italian Journal of Public Health 9 (2012): e7539.

26. Xu K. "Household catastrophic health expenditure : a multicountry analysis". The Lancet 362 (2003): 111-117.

\section{Volume 3 Issue 12 December 2019}

(C) All rights are reserved by KC Bhuyan. 